\title{
Is left-handedness associated with a more pronounced age-related cognitive decline?
}

Citation for published version (APA):

van der Elst, W., van Boxtel, M. P. J., van Breukelen, G. J. P., \& Jolles, J. (2008). Is left-handedness associated with a more pronounced age-related cognitive decline? Laterality: Asymmetries of Body, Brain and Cognition, 13(3), 234-254. https://doi.org/10.1080/13576500701825693

Document status and date:

Published: 01/01/2008

DOI:

10.1080/13576500701825693

Document Version:

Publisher's PDF, also known as Version of record

\section{Please check the document version of this publication:}

- A submitted manuscript is the version of the article upon submission and before peer-review. There can be important differences between the submitted version and the official published version of record.

People interested in the research are advised to contact the author for the final version of the publication, or visit the DOI to the publisher's website.

- The final author version and the galley proof are versions of the publication after peer review.

- The final published version features the final layout of the paper including the volume, issue and page numbers.

Link to publication

\footnotetext{
General rights rights.

- You may freely distribute the URL identifying the publication in the public portal. please follow below link for the End User Agreement:

www.umlib.nl/taverne-license

Take down policy

If you believe that this document breaches copyright please contact us at:

repository@maastrichtuniversity.nl

providing details and we will investigate your claim.
}

Copyright and moral rights for the publications made accessible in the public portal are retained by the authors and/or other copyright owners and it is a condition of accessing publications that users recognise and abide by the legal requirements associated with these

- Users may download and print one copy of any publication from the public portal for the purpose of private study or research.

- You may not further distribute the material or use it for any profit-making activity or commercial gain

If the publication is distributed under the terms of Article $25 \mathrm{fa}$ of the Dutch Copyright Act, indicated by the "Taverne" license above, 


\title{
Is left-handedness associated with a more pronounced age-related cognitive decline?
}

\author{
Wim Van der Elst, Martin P. J. Van Boxtel, \\ Gerard J. P. Van Breukelen, and Jelle Jolles \\ Maastricht University, the Netherlands
}

\begin{abstract}
The effect of handedness on cognitive functioning has been the subject of much controversy. The influential "pathological left-handedness theory" posited by Coren and Halpern (1991) claims that left-handedness is probabilistically related to deviations from the neurological and cognitive norm. Many studies have failed to find negative effects of left-handedness on cognitive functioning, but most of these studies related handedness to cognition at one moment in time. Such studies do not exclude the possibility that sinistrality may be related to a more pronounced agerelated longitudinal decline in cognitive functions. This hypothesis was tested in the present study. In a longitudinal study involving a large population sample of cognitively intact people aged at least 50 years at baseline, we evaluated the effect of handedness on age-related decline in four major cognitive domains: speed of information processing, verbal learning, long-term verbal memory, and executive functioning. The results failed to provide support for the hypothesis that sinistrality is associated with a more pronounced age-related cognitive decline. Recommendations for future studies are provided.
\end{abstract}

Left-handedness has been associated with various pathology and associated problems, such as a shortened lifespan (Halpern \& Coren, 1988), a younger age of onset for Alzheimer's disease (Doody, Vacca, Massman, \& Liao, 1999), a more rapid cognitive decline in Alzheimer's disease patients (Rasmusson, Carson, Brookmeyer, Kawas, \& Brandt, 1996), mental retardation (Pipe, 1990), and gender identity disorder in boys (Zucker, Beaulieu, Bradley, Grimshaw, \& Wilcox, 2001). Based on these associations, some authors have concluded that left-handedness may be a "behavioural marker that is probabilistically related to a syndrome caused by a set of minor abnormalities in neurological development" (Coren \& Halpern, 1991, p. 102). According to this controversial "pathological left-handedness

Address correspondence to: Wim Van der Elst, Faculty of Health, Medicine and Life Sciences Faculty of Medicine, Department of Psychiatry and Neuropsychology, Maastricht University, 6200 MD, Maastricht, the Netherlands. E-mail: W.vanderelst@NP.unimaas.nl

(C) 2008 Psychology Press, an imprint of the Taylor \& Francis Group, an Informa business http://www.psypress.com/laterality

DOI: $10.1080 / 13576500701825693$ 
theory", a major cause of both sinistrality and minor abnormalities in the brain is hypothesised to be birth stress and prenatal complications such as a premature birth and low birth weight (Powls, Botting, Cooke, \& Marlow, 1996), caesarean section (Coren, 1995), older age of the mother at the time of delivery (Coren, 1990), and smoking by the mother during pregnancy (Bakan, 1991).

If sinistrality is indeed considered to be a probabilistic marker of minor abnormalities in the brain, one might expect that left-handed people deviate from the cognitive norm (Coren \& Halpern, 1991). Some empirical support for this prediction has been provided (De Agostini \& Dellatolas, 2001; Halpern, Haviland, \& Killian, 1998; Lamm \& Epstein, 1999; Natsopoulos, Kiosseoglou, Xeromeritou, \& Alevriadou, 1998). However, most studies with non-clinical populations have found no differences between the cognitive abilities of left-handed people and those of right-handed people (Farwell \& Temkin, 1994; Hardyck, Petrinovich, \& Goldman, 1976; Peters, 1991; Porac \& Searleman, 2002; Van der Elst, Van Boxtel, Van Breukelen, \& Jolles, 2006a; Whittington \& Richards, 1991), or even reported superior cognitive abilities in sinistrals as compared to dextrals (Benbow, 1988; Kopiez, Galley, \& Lee, 2006). Thus, the empirical support for the prediction that left-handed people deviate from the cognitive norm is inconclusive and rather negative.

It is, however, important to note that the majority of previous studies related handedness to cognitive functioning at one moment in time. Such studies, therefore, do not exclude the possibility that handedness may be associated with differences in the longitudinal trajectories of cognitive ageing. Indeed, previous research has shown that the effects of neurodegenerative changes that are associated with ageing vary considerably across individuals (Scarmeas \& Stern, 2003, 2004; Stern, Silva, Chaisson, \& Evans, 1996). The large inter-individual variability in cognitive ageing trajectories is often explained in terms of the cognitive reserve theory (Satz, 1993). According to this theory, it is assumed that there is a critical threshold in reserve capacity that needs to be exceeded before functional cognitive deficits emerge. The amount of cognitive reserve capacity that an individual possesses is affected by both active and passive components (Stern, 2002). Active components involve experiences such as education and occupational activities, while passive components involve brain structures that add capacity to efficient information processing, retrieval of memories, and problem solving. In view of the pathological left-handedness theory, it is conceivable that sinistrals possess a smaller amount of cognitive reserve capacity than dextrals because the minor abnormalities in their brains may interfere with educational or occupational activities (active components of reserve) as well as with the optimal development of certain brain structures that are involved in cognition (passive components of reserve). Due to the smaller reserve 
capacity of left-handed people as compared to the reserve capacity of their right-handed counterparts, the effects of the neurodegenerative changes that are associated with ageing are expected to be more pronounced for sinistrals than for dextrals.

Consequently, we hypothesised that the age-related cognitive decline in left-handed people may be more pronounced than the age-related cognitive decline in right-handed people. This hypothesis was tested in the present study. We used the data of a large longitudinal study on the determinants of normal cognitive ageing (the Maastricht Ageing Study; Jolles, Houx, Van Boxtel, \& Ponds, 1995) to evaluate the effect of handedness on age-related longitudinal change in four major cognitive domains: speed of information processing, verbal learning, long-term verbal memory, and executive functioning.

\section{METHOD}

\section{Participants}

Data were derived from the Maastricht Ageing Study (MAAS; Jolles et al., 1995), a longitudinal study on the determinants of cognitive ageing. MAAS baseline measurements were conducted between 1993 and 1996 and involved a total sample of $N=1856$ cognitively intact people over the adult age range (24-81 years). In the present study we only included people who were aged 50 years or older at baseline. This was done because the effect of handedness on age-related cognitive decline was expected to be especially pronounced for older people, and because the follow-up frequency in the MAAS differed as a function of baseline age (i.e. 6 years for people less than 50 years of age at baseline and 3 years for people aged 50 years or older). A total sample of $N=966$ people was aged 50 years or older at baseline. These people did the Edinburgh Handedness Inventory (EHI; Oldfield, 1971), the Stroop ColourWord Test (SCWT; Stroop, 1935), and the Letter Digit Substitution Test (LDST; Van der Elst, Van Boxtel, Van Breukelen, \& Jolles, 2006b). Approximately three-quarters of this sample did the visual version of the Verbal Learning Test (VVLT; Rey, 1958; Van der Elst, Van Boxtel, Van Breukelen, \& Jolles, 2005), while the remainder did the auditory version of the Verbal Learning Test. We only used the data generated by the people who were administered the visual version of the VLT at baseline (i.e., $N=$ 709), because all participants were administered the VVLT at the two followup occasions and mode of presentation was found to affect performance significantly in earlier studies (Van der Elst et al., 2005).

Not all data were included in the analyses. The data of 12 people were excluded because they scored below 24 on the Mini-Mental State Examination (Folstein, Folstein, \& McHugh, 1975). Table 1 presents basic 
demographic data for the three age groups (50-59 years, 60-69 years, and $70+$ years) for the participants who were administered the SCWT and the LDST, and for the participants who were administered the VVLT. The first and second follow-up measurements were conducted 3 and 6 years after baseline, respectively - mean test-retest interval equalled 3.13 years $(S D .26)$ and 6.18 years $(S D .19)$, respectively.

As shown in Table 1, approximately $92.5 \%$ of the total sample was righthanded and about $7.5 \%$ was left-handed (as measured with the EHI, see below). The percentage of left-handed people was especially low in the older age group $(70+$ years). Level of education (LE) was measured by classifying the formal schooling of participants in one of three groups, namely those with at most primary education (LE low), those with junior vocational training (LE average), and those with senior vocational or academic training (LE high). At the first follow-up measurement, 753 people were administered the SCWT and the LDST, and 563 people did the VVLT. At the second follow-up measurement, 674 people were administered the SCWT and the LDST, and 507 people did the VVLT. Dropout percentages between baseline and the first follow-up moment thus equalled $22.05 \%$ for the sample that did the SCWT and the LDST, and $20.59 \%$ for the sample that did the VVLT. Dropout percentages between baseline and the second follow-up equalled $30.23 \%$ for the sample that did the SCWT and the LDST, and $28.49 \%$ for the sample that did the VVLT.

Test scores were replaced by missing values in cases where the test assistant indicated that the test was not reliably administered (e.g., due to technical problems). This occurred with the test scores of 40, 21, and 31 people for the consecutive measurement occasions of the SCWT; with the test scores of 8,8 , and 8 people for the consecutive measurement occasions of the VVLT; and with the test scores of 8,5 , and 10 people for the consecutive measurement occasions of the LDST.

The ethnic background of all participants was Caucasian, and all participants were native Dutch speakers. More details regarding the sample frame, participant inclusion procedure, stratification criteria, attrition, and other aspects of the MAAS study have been described in detail elsewhere (Jolles et al., 1995).

\section{Procedure and instruments}

The EHI, SCWT, VVLT, and LDST were administered individually at the neuropsychological laboratory located at the Brain \& Behaviour Institute in Maastricht, the Netherlands. All tests were administered by test assistants who had been intensively trained in test administration by the neuropsychologists and physician of the project staff. Members of the project staff 
TABLE 1

Demographic characteristics of participants

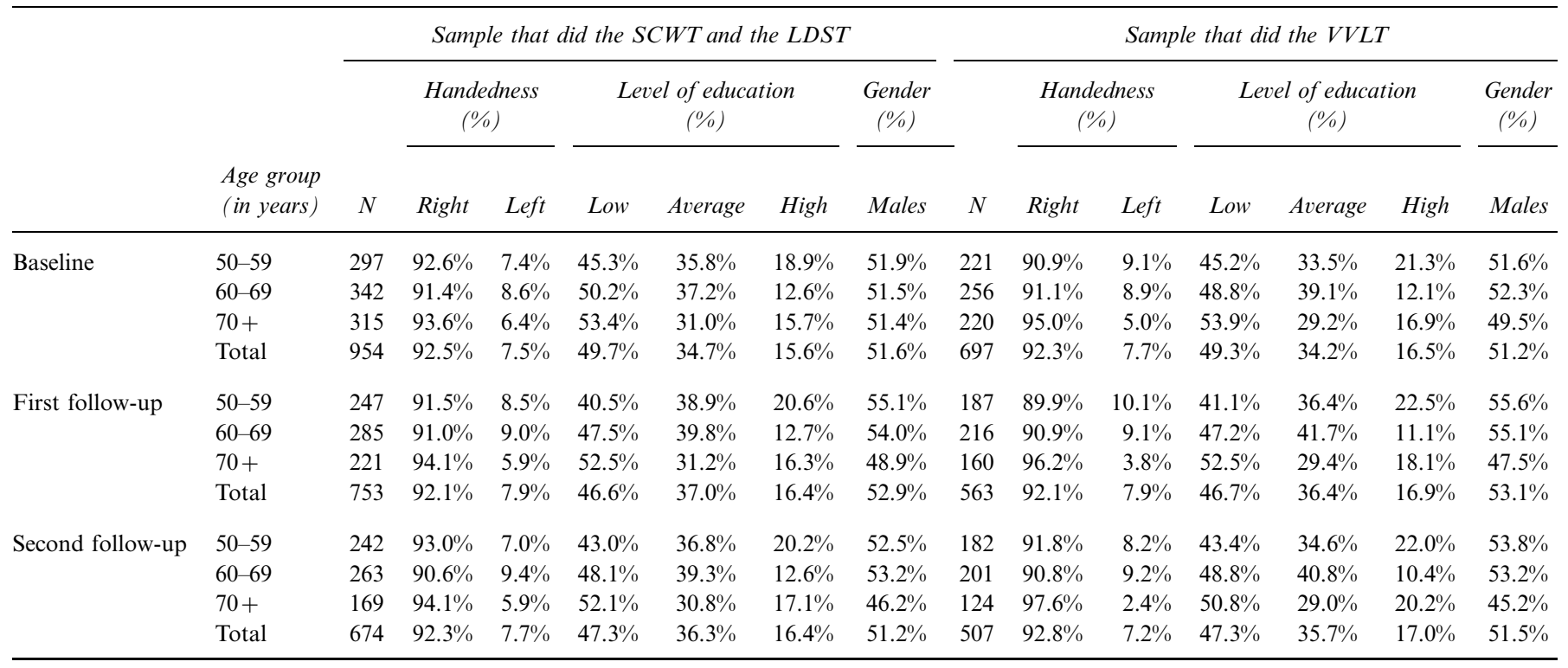

Demographic characteristics of the sample of participants who were administered the SCWT and the LDST at baseline, first follow-up and second followup (left), and for the sample of participants who were administered the VVLT at baseline, first follow-up and second follow-up (right), stratified by age group.

SCWT $=$ Stroop Color-Word Test; LDST $=$ Letter Digit Substitution Test; VVLT $=$ Visual Verbal Learning Test. 
visited the test assistants during assessment of the tests at least once a week to ensure uniform test administration and data collection.

The EHI is a commonly employed questionnaire to measure handedness (Dragovic, 2004). This test consists of 10 questions regarding a person's hand preference for different actions (writing, drawing, throwing, using scissors, using a toothbrush, using a knife without a fork, using a spoon, the upper hand when using a broom, striking a match, and opening the lid of a box). For each question, participants indicated their hand preference (right, left, or no preference). If eight or more questions were answered with "left" or with "right", the participant was considered to be left-handed or righthanded, respectively. If fewer than eight of the ten questions were answered with "left" or "right", the respondent was considered to be ambidextrous. Ambidextrous people were included in the left-handed group in the present study, as is commonly done in other studies (Coren, 1995; Porac \& Friesen, 2000).

The SCWT was used to measure cognitive flexibility and control (Uttl \& Graf, 1997) or executive functioning (Moering, Schinka, Mortimer, \& Graves, 2004). The SCWT version that was used in the present study (Hammes, 1973) consisted of three subtasks with 100 stimuli each. These three subtasks displayed names of colours (red, blue, yellow, green) in random order printed in black ink, solid colour patches in one of these four basic colours, and colour words printed in an incongruous ink colour (i.e., the word yellow printed in red ink), respectively. The participants were instructed to read the words (subtask one), name the colours (subtask two), and name the ink colour of the printed words (subtask three) as quickly and as accurately as possible. The time needed to complete the SCWT subtask 3 (measured in seconds) served as the outcome variable. The SCWT versions used at baseline and the two follow-up occasions were identical (no parallel test versions were used because we considered recollection of the test contents by participants to be unlikely).

The VVLT was used to measure different aspects of verbal memory (Schmidt, 1996). In this test, 15 words were presented one by one on a computer screen in a fixed order. As soon as the presentation stopped, the participants were asked to repeat as many words as possible in any order. This procedure was repeated four more times. This was followed by a delay of approximately 20 minutes. Following this delay, participants were instructed to recall the words learned once more (note that participants were not informed beforehand that they would have to recall the words later). Finally, a recognition trial was administered. The total number of correctly recalled words summed over the first three trials (VVLT total recall $1-3)$, and the number of correctly recalled words after the 20-minute delay (VVLT delayed recall) served as outcome variables in the present study. Parallel VVLT versions were used at each measurement occasion because 
other studies have consistently shown that pronounced practice effects occur in verbal memory tests, even when test-retest intervals of several years are used (Schmidt, 1996).

The LDST was used to measure general speed of information processing. This test is procedurally identical to substitution tests developed earlier such as the Digit Symbol Substitution Test (Wechsler, 1981). The LDST key consists of the numbers 1 to 9 paired with a different letter. Participants were required to replace the randomised letters with the appropriate digits as quickly and accurately as possible. The number of correct substitutions made in 60 seconds served as the dependent variable. The LDST versions used at each measurement occasion were identical (no parallel test versions were used because we considered recollection of the test contents by participants to be unlikely).

The cognitive abilities that are quantified by the time needed to complete SCWT subtask 3 (measured in seconds), the VVLT total recall 1-3 score, the VVLT delayed recall score, and the LDST score are hereafter referred to as measures of executive functioning, verbal learning, long-term verbal memory, and speed of information processing, respectively.

\section{Data analyses}

Linear mixed models analysis was used to evaluate the influence of handedness on cognitive change over time. Handedness, age, age ${ }^{2}$, gender, level of education, and time of measurement were used as predictors. We were especially interested in the effect of the handedness $\times$ age $\times$ time of measurement interaction to test the hypothesis that the age-related cognitive decline of sinistrals is more pronounced than the age-related cognitive decline of dextrals. In addition to this three-way interaction, all two-way interaction terms that could be constructed with the terms that constituted the three-way interaction (i.e., handedness $\times$ age, handedness $\times$ time of measurement, and age $\times$ time of measurement) were also included in the full models to make the models hierarchical. The effects of gender and education on cognitive change were not of primary interest in the present study, but were nonetheless included in the models because they have been found to influence cognitive change in previous studies (Anstey \& Christensen, 2000). The mixed model assumed fixed effects of all predictors and an unstructured $3 \times 3$ covariance matrix for the repeated measures. For complete data, this is equivalent to the multivariate method for ANOVA of repeated measures. Handedness was dummy coded with Right-handed $=1$ and Left-handed $=0$. Age was centred (Age = calendar age -65 ) before computing the quadratic terms and interactions to avoid multicollinearity (Marquardt, 1980). Gender was dummy coded with male $=1$ and female $=0$. 
Level of Education (LE) was dummy coded with two dummies (LE low and LE high) and LE average was used as the reference category. Time of measurement was dummy coded with two dummies (first follow-up and second follow-up), and baseline measurement was used as the reference category. The full models were then reduced in a stepwise hierarchical manner by eliminating the least significant predictor if its two-tailed $p$-value was above .005 . No predictor was removed from the model as long as it was also included in a higher-order term in the model. Deviance measures (i.e., $-2 \log$ likelihood values) were calculated for the full models and for the reduced models (note that a lower deviance measure corresponds to a better fit of the model). The fit of the full models was compared with the fit of the reduced models by means of likelihood ratio tests (for details, see Verbeke \& Molenberghs, 2000). When the fit of the reduced models was not significantly worse than the fit of the full models, the more parsimonious models were preferred. Linearity, normality of the residuals (normal distribution of the residuals for the three measurement moments), and homoscedasticity (homogeneous variance of the residuals over the range of the predicted scores, for the three measurement occasions) were examined graphically and analytically.

In addition, the association between handedness and dropout was evaluated. It is important to evaluate dropout patterns because non-random attrition that is related to the variable of interest (i.e., handedness) may in principle invalidate the conclusions that are drawn from the analyses of longitudinal data, although the mixed regression used for our primary analyses is valid even under such dropout (for details see Verbeke and Molenberghs, 2000). Binary logistic regression analysis was used to evaluate the effect of handedness on attrition (from baseline to the first follow-up, and from baseline to the second follow-up). Age, age ${ }^{2}$, gender, and level of education were also included in the models (as well as all possible two- and three-way interactions between these variables) because previous research suggested that these variables were related to dropout and should therefore be controlled for (Van Beijsterveldt et al., 2002; Van der Elst, Van Boxtel, Van Breukelen, \& Jolles, 2008). Age, age ${ }^{2}$, gender, and level of education were coded as described above in the multilevel models. Separate analyses were conducted for the sample that did the SCWT and the LDST, and for the sample that did the VVLT, because the sample that did the VVLT was a sub-sample of the sample that did the SCWT and the LDST, with different dropout percentages (see the Participants section). The full logistic regression models were reduced in a stepwise manner by eliminating the least significant predictor if its two-tailed $p$-value was above .005. Lower-order terms were never removed from the model as long as they were part of a higher-order term in the model. People who dropped out were assigned the code 1 , while people who remained in the study were given the code 0 . 
Multicollinearity and influential cases were checked for in each model by calculating Variance Inflation Factors and Cook's distances, respectively.

All analyses were conducted using SPSS 14.0 for Windows, with alpha= .005 for all analyses (a lower alpha level was chosen in order to avoid Type I errors due to multiple testing).

\section{RESULTS}

\section{Descriptive data}

Handedness was not significantly correlated with any of the cognitive ability measures at any of the measurement moments (the maximum correlation between handedness and cognitive ability equalled .08 , all $p>.01$ ). Figure 1 presents the mean scores of the cognitive ability measures per measurement moment for complete cases, stratified by handedness. Figure 1 suggests that there were no significant differences between the cognitive abilities of leftand right-handers at any measurement moment, but the data in this figure were not corrected for confounding factors such as age, gender, and education. The analyses presented below take these confounders into account. Note that the mean scores of most cognitive ability measures increased as a function of measurement moment (especially from baseline to the first follow-up moment, see Figure 1), which suggests that practice effects occurred on the cognitive tests (see the Discussion).

\section{Handedness and cognitive decline}

The final models of the hierarchical linear mixed models procedure are presented in Table 2. Table 3 compares the fit of these final models with the fit of the full models. As shown in Table 3, the fit of the final models was not significantly worse than the fit of the full models (i.e., all $p$ values of the $\chi^{2}$ difference tests were at least .15). Model assumptions of linearity, normality of the residuals, and homoscedasticity were generally met, with the exception of a trend to positively skewed distributions of the residuals of the SCWT trial 3 score at each measurement occasion. For this reason, the SCWT trial 3 score was square root transformed. The residuals were sufficiently normally distributed after this transformation.

The handedness $\times$ age $\times$ time of measurement interaction (captured by the handedness $\times$ age $\times$ first follow-up and the handedness $\times$ age $\times$ second follow-up interaction terms) was not significant in any of the final models (all $p>.17$ ). In addition, after removing the three-way interaction from the models, none of the two-way interactions involving handedness was significant (i.e., handedness $\times$ age, handedness $\times$ first follow-up and 

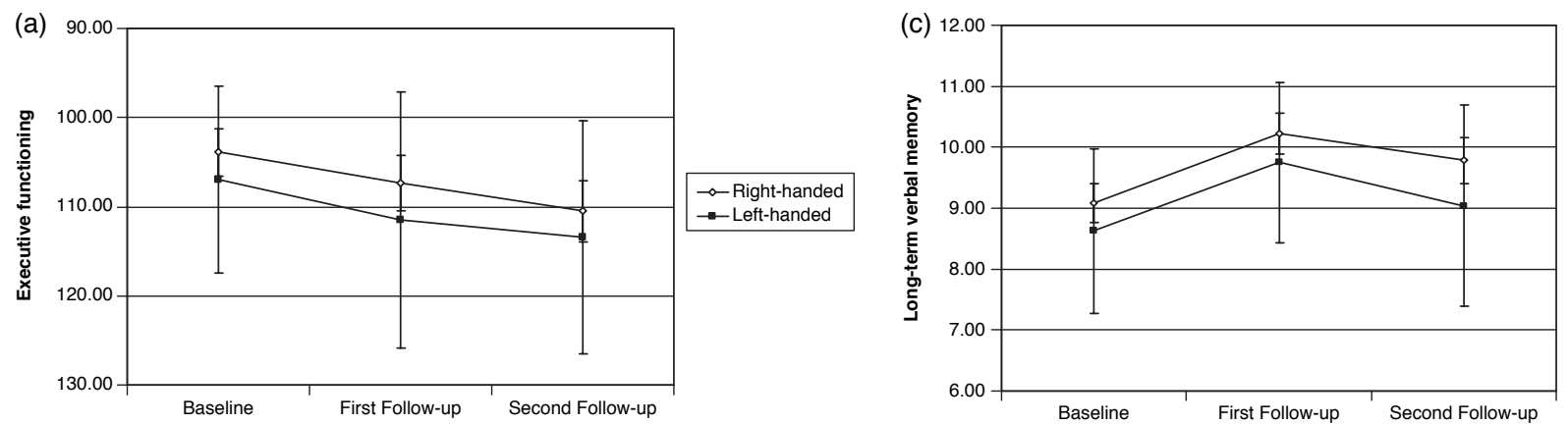

\section{$\rightarrow$ Right-handed}

$\rightarrow-$ Left-handed
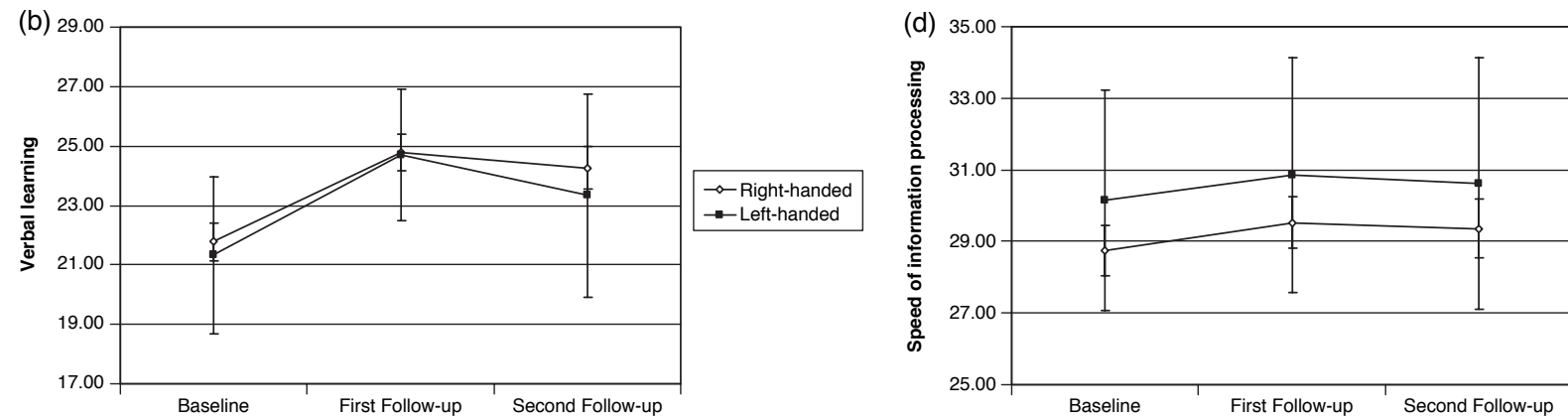

Mean scores for the executive functioning (a), verbal learning (b), long-term verbal memory and (c), speed of information processing (d), measures the consecutive measurement moments (and 99\% Confidence Intervals), stratified by handedness. Note. For the sake of clarity, the order of the values on the Y-axis has been inverted for the executive functioning measure (because lower or higher SCWT subtask 3 scores indicate better or worse performance, respectively). 
TABLE 2

Final mixed models

\begin{tabular}{|c|c|c|c|c|}
\hline Cognitive function & Variable & Estimate & $S E$ & $T$ \\
\hline \multirow[t]{10}{*}{ Executive functioning } & (constant) & 9.771 & .081 & $9.771^{* *}$ \\
\hline & Age & .062 & .004 & $.062^{* *}$ \\
\hline & $\mathrm{Age}^{2}$ & .003 & .001 & $.003^{* *}$ \\
\hline & Gender & .205 & .072 & $.205^{*}$ \\
\hline & LE low & .596 & .079 & $.596^{* *}$ \\
\hline & LE high & -.261 & 107 & -.261 \\
\hline & First follow-up & .272 & .033 & $.272^{* *}$ \\
\hline & Second follow-up & .469 & .038 & $.469^{* *}$ \\
\hline & Age $\times$ First follow-up & .027 & .004 & $.027^{* *}$ \\
\hline & Age $\times$ Second follow-up & .040 & .005 & $.040^{* *}$ \\
\hline \multirow[t]{8}{*}{ Long-term verbal memory } & (constant) & 9.816 & .218 & $44.996^{* *}$ \\
\hline & Age & -.125 & .011 & $-11.505^{* *}$ \\
\hline & $\mathrm{Age}^{2}$ & -.005 & .001 & $-3.431^{* *}$ \\
\hline & Gender & -1.006 & 190 & $-5.307^{* *}$ \\
\hline & LE low & -.845 & 209 & $-4.042^{* *}$ \\
\hline & LE high & .575 & 279 & 2.057 \\
\hline & First follow-up & 1.002 & .100 & $10.006^{* *}$ \\
\hline & Second follow-up & .549 & .112 & $4.895^{* *}$ \\
\hline \multirow[t]{9}{*}{ Verbal learning } & (constant) & 22.803 & .361 & $63.250^{* *}$ \\
\hline & Age & -.195 & .022 & $-8.722^{* *}$ \\
\hline & Gender & -1.877 & .343 & $-5.472^{* *}$ \\
\hline & LE low & -1.820 & .378 & $-4.811^{* *}$ \\
\hline & LE high & 1.138 & .502 & 2.266 \\
\hline & First Follow-up & 2.741 & .195 & $14.093^{* *}$ \\
\hline & Second Follow-up & 2.085 & .225 & $9.261^{* *}$ \\
\hline & Age $\times$ First Follow-up & -.067 & .023 & $-2.906^{*}$ \\
\hline & Age $\times$ Second Follow-up & -.096 & .027 & $-3.537^{* *}$ \\
\hline \multirow[t]{8}{*}{ Speed of information processing } & (constant) & 29.647 & .302 & $98.119^{* *}$ \\
\hline & Age & -.314 & .021 & $-14.921^{* *}$ \\
\hline & LE low & -4.229 & .391 & $-10.811^{* *}$ \\
\hline & LE high & 1.889 & .534 & $3.540^{* *}$ \\
\hline & First Follow-up & .413 & .135 & $3.065^{*}$ \\
\hline & Second Follow-up & .103 & .155 & .665 \\
\hline & Age $\times$ First Follow-up & -.087 & .016 & $-5.491^{* *}$ \\
\hline & Age $\times$ Second Follow-up & -.174 & .019 & $-9.366^{* *}$ \\
\hline
\end{tabular}

Coefficients, standard errors, T-values and their significance levels for the final mixed models with executive function, long-term verbal memory, verbal learning, and speed of information processing as outcome variables. The full models included handedness, age, age ${ }^{2}$, gender, LE low, LE high, first follow-up, second follow-up, handedness $\times$ age, handedness $\times$ first follow-up, handedness $\times$ second follow-up, age $\times$ first follow-up, age $\times$ second follow-up, handedness $\times$ age $\times$ first follow-up, and handedness $\times$ age $\times$ second follow-up as predictors.

Handedness is not presented in these models because only the significant predictors that remained in the models after the hierarchical procedure are included. Executive functioning, long-term verbal memory, verbal learning, and speed of information processing were quantified by the square root transformed time to complete subtask 3 of the SCWT (measured in seconds), the VVLT delayed recall score, the VVLT total recall 1-3 score, and the LDST score, respectively. $\mathrm{LE}=$ level of education, $\mathrm{SE}=$ standard error.

Coding of the predictors: Age $=$ calendar age $-65 ; \mathrm{Age}^{2}=(\text { calendar age }-65)^{2}$; Gender: male $=1$, female $=0 ; \mathrm{LE}$ low: low education $=1$, average or high education $=0 ; \mathrm{LE}$ high: high education $=1$, low or average education $=0$; First follow-up: First follow-up =1, baseline or second follow-up =0; Second follow-up: Second follow-up =1, baseline or first follow-up $=0$.

$$
{ }^{*} p<.005 ;{ }^{* *} p<.001 \text {. }
$$


TABLE 3

Chi-square difference tests that compare the fit of the full models and the fit of the final models that result from a hierarchical procedure

\begin{tabular}{|c|c|c|c|c|c|c|}
\hline \multirow[b]{2}{*}{ Cognitive function } & \multicolumn{2}{|c|}{ Full model } & \multicolumn{2}{|c|}{ Final model } & \multicolumn{2}{|c|}{$\chi^{2}$ difference test } \\
\hline & $-2 L L$ & $\begin{array}{l}\text { Number of } \\
\text { parameters }\end{array}$ & $-2 L L$ & $\begin{array}{l}\text { Number of } \\
\text { parameters }\end{array}$ & $\begin{array}{c}\chi^{2} \text { difference } \\
\text { value }(d f)\end{array}$ & $p$ value \\
\hline Executive functioning & 5942.45 & 22 & 5950.67 & 16 & $8.22(6)$ & 0.22 \\
\hline $\begin{array}{l}\text { Long-term verbal } \\
\text { memory }\end{array}$ & 8042.51 & 22 & 8054.47 & 14 & $11.96(8)$ & 0.15 \\
\hline Verbal learning & 10188.88 & 22 & 10198.01 & 15 & $9.13(7)$ & 0.24 \\
\hline $\begin{array}{l}\text { Speed of information } \\
\text { processing }\end{array}$ & 13354.05 & 22 & 13361.21 & 14 & $7.16(8)$ & 0.52 \\
\hline
\end{tabular}

Executive functioning, long-term verbal memory, verbal learning, and speed of information processing were quantified by the square root transformed time to complete subtask 3 of the SCWT (measured in seconds), the VVLT delayed recall score, the VVLT total recall $1-3$ score, and the LDST score, respectively. $-2 \mathrm{LL}=-2 \mathrm{Log}$ Likelihood.

handedness $\times$ second follow-up; all $p>.05$ ). After removing those interactions, the main effect of handedness was not significant either (all $p>.05$ ) (see Table 2).

The final models showed that the occurrence of changes over time in executive functioning, verbal learning, and speed of information processing were age-dependent (i.e., the age $\times$ first follow-up and age $\times$ second followup interaction terms were significant). Thus, the decline over time in these cognitive functions was especially pronounced for older people when compared to their younger counterparts. The change over time in longterm verbal memory was not affected by age; constant changes of about 1 and 0.5 words were predicted from baseline to the first follow-up and from baseline to the second follow-up over the entire age-range in the sample (see Table 2). All cognitive functions were influenced by the level of education: the cognitive abilities of poorer-educated people were lower as compared to the cognitive abilities of their higher-educated counterparts at each measurement moment. Additionally, executive functioning, verbal learning, and long-term verbal memory capacities were superior in women as compared to men at each measurement occasion.

\section{Handedness and dropout}

Table 4 shows the final binary logistic regression models that predicted dropout after 3 and after 6 years in the sample of people who did the SCWT and the LDST, and in the sample of people who did the VVLT. There was no 
TABLE 4

Final binary logistic regression models that predict dropout between baseline and the first follow-up and between baseline and the second follow-up for the participants who did the SCWT and the LDST, and for the participants who did the VVLT

\begin{tabular}{|c|c|c|c|c|c|c|}
\hline Outcome & Variable & $B$ & $S E B$ & Wald $\chi^{2}$ & $e^{B}$ & $R^{2}{ }_{N}$ \\
\hline \multicolumn{7}{|l|}{ Sample of participants who did the SCWT and the LDST } \\
\hline \multirow[t]{4}{*}{ Dropout between baseline and the first follow-up } & (constant) & -1.699 & .155 & $120.414^{* *}$ & 0.183 & \\
\hline & Age & .038 & .010 & $15.169^{* *}$ & 1.039 & \\
\hline & LE low & .568 & .189 & $9.034^{*}$ & 1.765 & \\
\hline & LE High & .089 & .270 & 0.109 & 1.093 & .047 \\
\hline \multirow[t]{3}{*}{ Dropout between baseline and the second follow-up } & (constant) & -1.175 & .109 & $115.815^{* *}$ & 0.309 & \\
\hline & Age & .070 & .009 & $63.283^{* *}$ & 1.073 & \\
\hline & $\mathrm{Age}^{2}$ & .003 & .001 & $7.962^{*}$ & 1.003 & .121 \\
\hline \multicolumn{7}{|l|}{ Sample of participants who did the VVLT } \\
\hline \multirow[t]{3}{*}{ Dropout between baseline and the first follow-up } & (constant) & -1.783 & .148 & $145.390^{* *}$ & 1.039 & \\
\hline & Age & .038 & .011 & $12.334^{* *}$ & 1.039 & \\
\hline & $\mathrm{Age}^{2}$ & .004 & .001 & $9.755^{*}$ & 1.004 & .054 \\
\hline \multirow{2}{*}{ Dropout between baseline and the second follow-up } & Age & .070 & .010 & $45.260^{* *}$ & 1.073 & \\
\hline & $\mathrm{Age}^{2}$ & .004 & .001 & $9.722^{*}$ & 1.004 & .125 \\
\hline
\end{tabular}

The full models included handedness, age, age ${ }^{2}$, gender, LE low, LE high, and all possible two-way interactions as predictors.

Handedness is not presented in these models because only the significant predictors that remained in the models after the hierarchical procedure are included. SCWT $=$ Stroop Colour-Word Test; LDST $=$ Letter Digit Substitution Test; VVLT $=$ Visual Verbal Learning Test. LE $=$ level of education, $\mathrm{SE}=$ standard error; $R_{N}^{2}=$ Nagelkerke $R^{2}$.

Coding of the predictors: Age $=$ calendar age $-65 ; \mathrm{Age}^{2}=(\text { calendar age }-65)^{2} ;$ LE low: low education $=1$, average or high education $=0 ;$ LE high: high education $=1$, low or average education $=0$.

${ }^{*} p<.005 ;{ }^{* *} p<.001$ 
serious influence of outliers (maximum Cook's distance in the final models equalled .07) or multicollinearity (maximum Variance Inflation Factor in the final models equalled 1.23) for any of these models.

As shown in Table 4, neither the main effect of handedness nor any of the interaction terms with handedness significantly affected dropout. The predicted probabilities to dropout between baseline and the first followup, and between baseline and the second follow-up, increased as a function of age at baseline in the sample of people who did the SCWT and the LDST, and in the sample of people who did the VVLT. Lower education was associated with a higher predicted probability to dropout after 3 years in the sample of people who did the LDST and the SCWT.

\section{DISCUSSION}

The pathological left-handedness theory claims that sinistrality is probabilistically related to minor deviations from the neurological and cognitive norm (Coren \& Halpern, 1991). The reserve theory suggests that the negative effects of ageing on cognitive functioning are more pronounced in people who possess a smaller amount of reserve capacity (e.g., due to minor abnormalities in their brain). Based on these theories, we hypothesised that the age-related cognitive decline in sinistrals would be more pronounced than the age-related cognitive decline in dextrals. This hypothesis was evaluated in a longitudinal study that involved a large population sample of cognitively healthy middle-aged and older people. Age-related changes after 3 and 6 years were evaluated in four major cognitive domains: executive functioning, verbal learning, long-term verbal memory, and speed of information processing. The results of the present study were straightforward and indicated that left-handed people did not show a more pronounced age-related cognitive decline than their right-handed counterparts. In fact, handedness was not associated with cognitive functioning at any of the measurement moments (i.e., none of the two-way interactions involving handedness was significant after removing the three-way interaction from the mixed models, and the main effect of handedness was not significant either after removing the two-way interactions involving handedness).

Our study was the first one to evaluate associations between handedness and longitudinal age-related changes in specific cognitive abilities that were quantified by using well-validated cognitive tests in a large sample of middleaged and elderly adults. The data were analysed using linear mixed models analyses, a technique generally considered to be the best statistical method to account for incomplete observations due to factors such as attrition. The results of linear mixed models analyses are valid even if attrition depends on the observed covariates or previous repeated measures (Little, 1995; Schafer 
\& Graham, 2002; Verbeke \& Molenberghs, 2000). In the present study, the demographical variables affected dropout, but handedness did not (see the final logistic regression models in Table 4). The finding that handedness was not associated with attrition is not only relevant from a methodological viewpoint, but also provides indirect evidence against the pathological lefthandedness theory (in addition to the direct evidence against this theory, see the results of the linear mixed models analyses in Table 2). Indeed, the pathological left-handedness theory would predict higher dropout percentages in sinistrals than in dextrals for two reasons. First, earlier longitudinal studies have shown that dropouts tend to have lower cognitive abilities than people who do not drop out (e.g., Levin, Katzen, Klein, \& Llabre, 2000; Van Beijsterveldt et al., 2002). Thus, if sinistrals have lower cognitive abilities than dextrals - as is claimed by the pathological left-handedness theorythey should drop out more often than dextrals. Second, the pathological lefthandedness theory claims that sinistrality is associated with higher mortality rates (Coren \& Halpern, 1991).

The large sample size of the present study increases our confidence in the conclusions that were drawn. However, our results should be replicated and extended in future research. Several improvements to the present study's design can be suggested. First, according to the pathological left-handedness theory, sinistrality is considered to be a probabilistic marker for abnormalities in the brain (Coren \& Halpern, 1991). Thus, it is argued that the probability that a left-handed person suffers from neurological abnormalities is higher than the probability that a right-handed person suffers from similar abnormalities in the brain (note that there are also more extreme theories that claim that left-handedness is always the result of a pathological cause; see Bakan, Dibb, \& Reed, 1973). Birth stressors are assumed to be a major cause of both left-handedness and neurological abnormalities. It is therefore conceivable that only the subgroup of left-handed people who also experienced relatively high birth stress are at risk of a more pronounced age-related cognitive decline, as compared to left-handed people who did not experience birth stressors and as compared to dextrals. Consequently, future research should take factors such as birth stress into account when evaluating the relationship between handedness and age-related cognitive decline. Several practical complications may arise when establishing such a study. For example, it may be difficult to measure birth stress in a reliable way when self-report methods are used, particularly in older adults when no parental confirmation or birth records can be obtained. In addition, the base rate of left-handed people who also experienced relatively high birth stress may be low in the general population, which would make it difficult to establish a study with sufficient statistical power.

Second, we dichotomised handedness and included ambidextrous people in the left-handed group. This classification procedure of handedness is in 
agreement with recommendations made in the literature (Bryden, McManus \& Bultman-Fleming, 1994; Coren, 1995; Porac \& Friesen, 2000), but not all researchers may agree with this classification procedure. For this reason, we also evaluated whether using a trichotomous measure of handedness (sinistrals, ambidexters, and dextrals) rather than a dichotomous measure (sinistrals and dextrals) affected the results. Thus linear mixed models analyses with dummies for left-handed and right-handed people (and using ambidexters as the reference category) were conducted (in addition to the demographical variables as predictors). No differences in the results were found: neither the three-way interactions, nor the two-way interactions nor the main effects of handedness were significant (all $p>.06$ ) in any of the models (data not shown). Note also that some researchers have argued that handedness is a continuous rather than a categorical variable (e.g., Annett, 1998). Unfortunately, we could not evaluate whether the use of a (semi)continuous measure of handedness (e.g., the raw EHI score) rather than a categorical measure affected the results because the raw EHI scores were not stored in the MAAS database and it is not possible to retrieve this information. Future studies should thus include continuous handedness measures in addition to the categorical handedness measures.

Third, we did not take the influence of social pressure on preferred handedness into account in the present study. It is a well-known fact that there were strong social directives against left-handedness until a few decades ago (and perhaps even today, at least in certain more urban societies; see Zverev, 2006). Social pressure can function in any of the following ways: (1) it may exert no influence whatsoever on preferred handedness; (2) it may affect certain behaviours that are under relatively high social pressure (such as writing and eating) while behaviours that are under less social pressure are not affected (such as throwing a ball); or (3) it may become generalised to all activities (De Agostini, Khamis, Ahui, \& Dellatolas, 1997). The extent to which social pressure is successful in shifting the preferred hand from the left to the right side may be related to the age at which the pressure was exerted. Therefore, future studies that evaluate the influence of handedness on age-related cognitive decline should also consider factors such as the social pressure that was exerted to sinistrals to switch their hand preference to the right side, as well as the age at which the social pressure occurred. Different authors have also argued that footedness is as good an indicator of laterality as handedness, or even better because footedness is a less socially biased measure of laterality than handedness (Elias \& Bryden, 1998; Watson, Pusakulich, Hermann, Ward, \& Wyler, 1993). It may therefore also be useful to measure footedness in addition to handedness in future studies.

Fourth, the present study evaluated the effect of handedness on age-related decline in speed of information processing, verbal learning, 
long-term verbal memory, and executive functioning. These cognitive domains are of major theoretical and clinical importance in ageing studies such as the MAAS because previous studies have found that especially these cognitive abilities are among the first ones that decline with increasing age (Craik \& Salthouse, 2000; LaRue, 1992; Spreen \& Strauss, 1998). However, it should be noted that the cognitive abilities that were considered in the present study were mainly left hemispheric, which rises the question to what extent the results of the present study can be generalised to righthemispheric cognitive abilities. Some authors have indeed suggested that the effect of handedness on left and right hemispheric cognitive abilities is fundamentally different; i.e., that right-handed people have superior verbal skills due to non-optimal development of the left hemisphere (this hypothesis was not confirmed by the results of the present study), while left-handed people have superior visuospatial skills due to overdeveloped functioning of the right hemisphere (Annett \& Kilshaw, 1983; Geschwind \& Galaburda, 1987). In addition, it has also been suggested that ageing affects right hemispheric cognitive functions more strongly than left hemispheric cognitive functions (the right hemi-ageing hypothesis; Albert \& Moss, 1988). It is thus possible that handedness affects the age-related changes in right and left hemispheric cognitive functions differentially. Future studies should evaluate this issue in more detail.

Fifth, the present study used a longitudinal design to evaluate the effect of handedness on age-related cognitive decline. Longitudinal studies have significant methodological advantages as compared to cross-sectional studies (e.g., they can distinguish age effects and cohort effects), but a disadvantage of longitudinal studies is that they tend to underestimate the true change in cognition over time because practice effects occur (Hayslip \& Panek, 1989). In the present study, most cognitive measures were indeed found to improve over time (see Figure 1), although parallel test versions were used (when appropriate) to avoid the occurrence of practice effects. The reason for this is that procedural learning cannot be circumvented by using parallel test forms (Benedict \& Zgaljardic, 1998; Claus, Mohr, \& Chase, 1991; Schmidt, 1996). It is thus difficult to attribute the changes that occur in the cognitive measures over time to "true changes" in the underlying constructs that are measured by the cognitive tests. The observed changes over time in the cognitive test scores reflect the "net effect" of the positive effects of procedural learning, and the negative effects of the true decline over time in the underlying cognitive abilities. The net effect of these influences was thus positive for the long-term memory, verbal learning, and speed of information processing measures (i.e., the positive effect of procedural learning was larger than the negative effect of the true decline over time in the underlying cognitive abilities), and negative for the executive functioning measure (i.e., the positive effect of procedural learning was 
smaller than the negative effect of the true decline over time in the underlying cognitive abilities). It is not possible to distinguish the effects of the "true change" in the underlying cognitive abilities from the effects of procedural learning in the present study, which is a common problem in all longitudinal studies that use repeated measurements with cognitive tests.

Sixth, the conclusions that were drawn in the present study were based on data that were gathered over a period of 6 years. It is possible that the effect of handedness on age-related cognitive change is quite small and may only be detected when a period of more than 6 years is used. In 2008 data of the 12-year follow-up of the MAAS will become available. Future analyses on these data may shed more light on the issue of the relevance of the length of the time interval to evaluate the effect of handedness on age-related cognitive changes.

Manuscript received 12 April 2007

Manuscript accepted 17 October 2007

First published online 31 January 2008

\section{REFERENCES}

Albert, M. S., \& Moss, M. B. (1988). Geriatric neuropsychology. New York: Guilford Press.

Annett, M. (1998). Handedness and cerebral dominance: The right shift theory. Journal of Neuropsychiatry and Clinical Neuroscience, 10, 459-469.

Annett, M., \& Kilshaw, D. (1983). Right- and left-hand skill II: Estimating the parameters of the distribution of L-R differences in males and females. British Journal of Psychology, 74, 269-283.

Anstey, K., \& Christensen, H. (2000). Education, activity, health, blood pressure and apolipoprotein $\mathrm{E}$ as predictors of cognitive change in old age: A review. Gerontology, 46, 163-177.

Bakan, P. (1991). Handedness and maternal smoking during pregnancy. The International Journal of Neuroscience, 56, 161-168.

Bakan, P., Dibb, G., \& Reed, P. (1973). Handedness and birth stress. Neuropsychologia, 11, 363-366.

Benbow, C. P. (1988). Sex differences in mathematical reasoning ability in intellectually talented preadolescents: Their nature, effects and possible causes. Behavioral and Brain Sciences, 11, 169-232.

Benedict, R., \& Zgaljardic, D. (1998). Practice effects during repeated administrations of memory tests with and without alternate forms. Journal of Clinical \& Experimental Neuropsychology, 20, 339-352.

Bryden, M. P., McManus, I. C., \& Bultman-Fleming, M. B. (1994). Evaluating the empirical support for the Geschwind-Behan-Galaburda model of cerebral lateralisation. Brain and Cognition, 26, 312-326.

Claus, J., Mohr, E., \& Chase, T. (1991). Clinical trials in dementia: Learning effects with repeated testing. Journal of Psychiatry \& Neuroscience, 16, 1-4.

Coren, S. (1990). Relative risk of left-handedness in offspring as a function of maternal age at parturition. New England Journal of Medicine, 322, 1673.

Coren, S. (1995). Family patterns in handedness: Evidence for indirect inheritance meditated by birth stress. Behavior Genetics, 25, 517-524. 
Coren, S., \& Halpern, D. F. (1991). Left-handedness: A marker for decreased survival fitness. Psychological Bulletin, 109, 90-106.

Craik, F. I. M., \& Salthouse, T. A. (2000). The handbook of ageing and cognition. Mahwah, NJ: Lawrence Erlbaum Associates Inc.

De Agostini, M., \& Dellatolas, G. (2001). Lateralities in normal children ages 3 to 8 and their role in cognitive performances. Developmental Neuropsychology, 20, 429-444.

De Agostini, M., Khamis, A. H., Ahui, A. M., \& Dellatolas, G. (1997). Environmental influences in hand preference: An African point of view. Brain and Cognition, 35, 151-167.

Doody, R. S., Vacca, J. L., Massman, P. J., \& Liao, T. (1999). The influence of handedness on the clinical presentation and neuropsychology of Alzheimer disease. Archives of Neurology, 56, $1133-1137$.

Dragovic, M. (2004). Towards an improved measure of the Edinburgh Handedness Inventory: A one-factor congeneric measurement model using confirmatory factor analysis. Laterality, 9, 411-419.

Elias, L., \& Bryden, M. P. (1998). Footedness is a better predictor of language lateralisation than handedness. Laterality, 3, 41-51.

Farwell, J. R., \& Temkin, N. R. (1994). Crossed dominance and its relationship to intelligence and academic achievement. Developmental Neuropsychology, 10, 473-479.

Folstein, M. F., Folstein, S. E., \& McHugh, P. R. (1975). Mini-Mental State: A practical method for grading the cognitive state of patients for the clinician. Journal of Psychiatric Research, 12, 189-198.

Geschwind, N., \& Galaburda, A. M. (1987). Cerebral lateralisation. London: MIT Press.

Halpern, D. F., \& Coren, S. (1988). Do right-handers live longer? Nature, 333, 213.

Halpern, D. F., Haviland, M. G., \& Killian, C. D. (1998). Handedness and sex differences in intelligence: Evidence from the Medical College Admission Test. Brain and Cognition, 38, 87101.

Hammes, J. (1973). De Stroop Kleur-Woord Test: Handleiding [The Stroop Color-Word Test: Manual]. Amsterdam: Swets \& Zeitlinger.

Hardyck, C., Petrinovich, L. F., \& Goldman, R. D. (1976). Left-handedness and cognitive deficit. Cortex, 12, 266-279.

Hayslip, B., \& Panek, P. E. (1989). Adult development and ageing. New York: Harper \& Row.

Jolles, J., Houx, P. J., Van Boxtel, M. P. J., \& Ponds, R. W. H. M. (1995). Maastricht Ageing Study: Determinants of cognitive ageing. Maastricht, The Netherlands: Neuropsych Publishers.

Kopiez, R., Galley, N., \& Lee, J. I. (2006). The advantage of a decreasing right-hand superiority: The influence of laterality on a selected musical skill (sight reading achievement). Neuropsychologia, 44, 1079-1087.

Lamm, O., \& Epstein, R. (1999). Left-handedness and achievements in foreign language studies. Brain and Language, 70, 504-517.

LaRue, A. (1992). Ageing and neuropsychological assessment. New York: Plenum Press.

Levin, B. E., Katzen, H. L., Klein, B., \& Llabre, M. L. (2000). Cognitive decline affects subject attrition in longitudinal research. Journal of Clinical and Experimental Neuropsychology, 22, 580-586.

Little, R. J. A. (1995). Modelling the dropout mechanism in repeated-measures studies. Journal of the American Statistical Association, 90, 1112-1121.

Marquardt, D. W. (1980). You should standardize the predictor variables in your regression models. Journal of the American Statistical Association, 75, 87-91.

Moering, R. G., Schinka, J. A., Mortimer, J. A., \& Graves, A. B. (2004). Normative data for elderly African Americans for the Stroop Color and Word Test. Archives of Clinical Neuropsychology, 19, 61-71. 
Natsopoulos, D., Kiosseoglou, G., Xeromeritou, A., \& Alevriadou, A. (1998). Do the hands talk on mind's behalf? Differences in language ability between left- and right-handed children. Brain and Language, 64, 182-214.

Oldfield, R. C. (1971). The assessment and analysis of handedness: The Edinburgh Inventory. Neuropsychologia, 9, 97-113.

Peters, M. (1991). Sex, handedness, mathematical ability and biological causation. Canadian Journal of Psychology, 45, 415-419.

Pipe, M. E. (1990). Mental retardation and left-handedness: Evidence and theories. In S. Coren (Ed.), Left-handedness: Behavioral implications and anomalies (pp. 293-318). Amsterdam: Elsevier.

Porac, C., \& Friesen, I. C. (2000). Hand preference side and its relation to hand preference switch history among old and oldest-old adults. Developmental Neuropsychology, 17, 225-239.

Porac, C., \& Searleman, A. (2002). The effects of hand preference side and hand preference switch history on measures of psychological and physical well-being and cognitive performance in a sample of older adult right- and left-handers. Neuropsychologia, 40, 2074-2083.

Powls, A., Botting, N., Cooke, R. W., \& Marlow, N. (1996). Handedness in very-low-birthweight (VLBW) children at 12 years of age: Relation to perinatal and outcome variables. Developmental Medicine and Child Neurology, 38, 594-602.

Rasmusson, D. X., Carson, K. A., Brookmeyer, R., Kawas, C., \& Brandt, J. (1996). Predicting rate of cognitive decline in probable Alzheimer's disease. Brain and Cognition, 31, 133-147.

Rey, A. (1958). L'examen clinique en psychologie. Paris: Presses Universitaires de France.

Satz, P. (1993). Brain reserve capacity on symptom onset after brain injury: A formulation and review of evidence for threshold theory. Neuropsychology, 7, 273-295.

Scarmeas, N., \& Stern, Y. (2003). Cognitive reserve and lifestyle. Journal of Clinical and Experimental Neuropsychology, 25, 625-633.

Scarmeas, N., \& Stern, Y. (2004). Cognitive reserve: Implications for diagnosis and prevention of Alzheimer's disease. Current Neurology and Neuroscience Reports, 4, 374-380.

Schafer, J. L., \& Graham, J. W. (2002). Missing data: Our view of the state of the art. Psychological Methods, 7, 147-177.

Schmidt, M. (1996). Rey Auditory Verbal Learning Test: A handbook. Los Angeles: Western Psychological Services.

Spreen, O., \& Strauss, E. (1998). A compendium of neuropsychological tests. New York: Oxford University Press.

Stern, R. A., Silva, S. G., Chaisson, N., \& Evans, D. L. (1996). Influence of cognitive reserve on neuropsychological functioning in asymptotic human immunodeficiency virus-1 infection. Archives of Neurology, 53, 148-153.

Stern, Y. (2002). What is cognitive reserve? Theory and research application of the reserve concept. Journal of the International Neuropsychological Society, 8, 448-460.

Stroop, J. (1935). Studies of interference in serial verbal reactions. Journal of Experimental Psychology, 18, 643-662.

Uttl, B., \& Graf, P. (1997). Color-word Stroop test performance across the adult life span. Journal of Clinical and Experimental Neuropsychology, 19, 405-420.

Van Beijsterveldt, C. E. M., van Boxtel, M. P. J., Bosma, H., Houx, P. J., Buntinx, F., \& Jolles, J. (2002). Predictors of attrition in a longitudinal cognitive ageing study: The Maastricht Ageing Study (MAAS). Journal of Clinical Epidemiology, 55, 216-223.

Van der Elst, W., Van Boxtel, M. P. J., Van Breukelen, G. J. P., \& Jolles, J. (2005). Rey's Verbal Learning Test: Normative data for 1855 healthy participants aged 24-81 years and the influence of age, sex, education, and mode of presentation. Journal of the International Neuropsychological Society, 11, 290-302.

Van der Elst, W., Van Boxtel, M. P. J., Van Breukelen, G. P. J., \& Jolles, J. (2006a). The concept shifting test: Adult normative data. Psychological Assessment, 18, 424-432. 


\section{VAN DER ELST ET AL.}

Van der Elst, W., Van Boxtel, M. P. J., Van Breukelen, G. P. J., \& Jolles, J. (2006b). The Letter Digit Substitution Test: Normative data for 1,858 healthy participants aged 24-81 from the Maastricht Ageing Study (MAAS): Influence of age, education, and sex. Journal of Clinical and Experimental Neuropsychology, 28, 998-1009.

Van der Elst, W., Van Boxtel, M. P. J., Van Breukelen, G. J. P., \& Jolles, J. (2008). Assessment of change in performance on the Stroop Color-Word Test, Verbal Learning Test of Rey, and Letter Digit Substitution Test after a test-retest interval of three years: The regression-based change approach. Journal of the International Neuropsychological Society, 14, 71-80.

Verbeke, G., \& Molenberghs, G. (2000). Linear mixed models for longitudinal data. New York: Springer.

Watson, G. S., Pusakulich, R. L., Hermann, B., Ward, J. P., \& Wyler, A. (1993). Hand, foot and language laterality: Evidence from Wada testing. Journal of Clinical and Experimental Neuropsychology, 15, 35.

Wechsler, D. (1981). Manual for the Wechsler Adult Intelligence Scale-Revised. New York: Psychological Corporation.

Whittington, J. E., \& Richards, P. N. (1991). Mathematical ability and the right-shift theory of handedness. Neuropsychologia, 29, 1075-1082.

Zucker, K. J., Beaulieu, N., Bradley, S. J., Grimshaw, G. M., \& Wilcox, A. (2001). Handedness in boys with gender identity disorder. Journal of Child Psychology and Psychiatry and Allied Disciplines, 42, 767-776.

Zverev, Y. P. (2006). Cultural and environmental pressure against left-hand preference in urban and semi-urban Malawi. Brain and Cognition, 60, 295-303. 